\title{
EDUCAÇÃO SANITÁRIA: CONHECIMENTO E PERCEPÇÃO DE PROFESSORES SOBRE O CONTEÚDO DA COLEÇÃO "SE LIGA GALERA" PROPOSTA PELA SEAPEC/RJ
}

\author{
SANITARY EDUCATION: KNOWLEDGE AND PERCEPTION \\ OF TEACHERS ABOUT THE CONTENT OF THE COLLECTION \\ “SE LIGA GALERA” PROPOSED BY SEAPEC/RJ
}

\begin{abstract}
EDUCACIÓN SANITARIA: CONOCIMIENTO Y PERCEPCIÓN DE LOS PROFESORES DEL CONTENIDO DE LA COLECCIÓN "SE LIGA GALERA" PROPUESTA POR LA SEAPEC/RJ
\end{abstract}

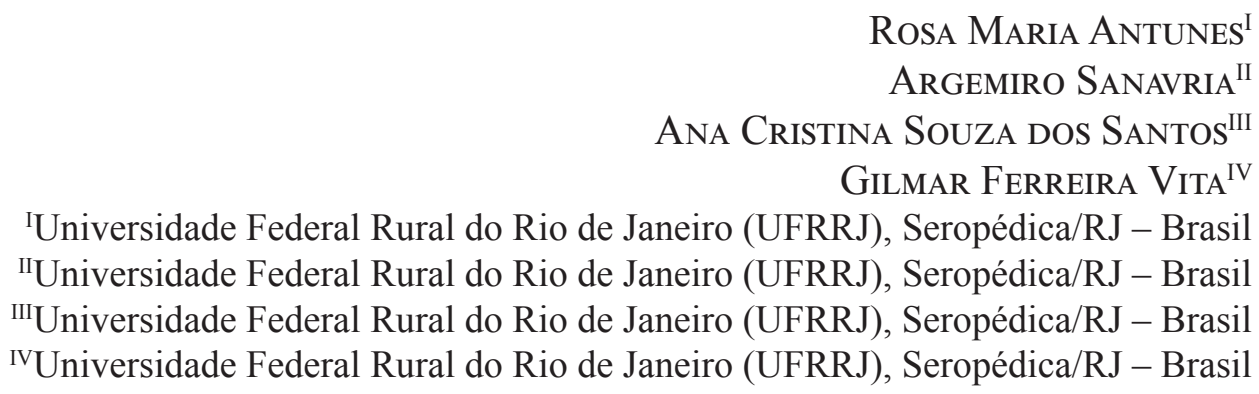

RESUMo Os objetivos desta pesquisa foram analisar o conhecimento de professores do Ensino Fundamental de escolas públicas rurais sobre o conteúdo da coleção "Se Liga Galera", proposta pela Secretaria de Estado de Agricultura e Pecuária do Rio de Janeiro (SEAPEC/ RJ), como estratégia voltada para a defesa agropecuária, ancorada em políticas de erradicação e controle de doenças, alimentos seguros e agrotóxicos; e, verificar a aceitação e percepção desses professores e educandos a respeito da temática estudada. O estudo também incluiu um terceiro objetivo, a saber, a capacitação dos professores, para que os conteúdos pudessem ser aplicados de forma interdisciplinar. A metodologia envolveu a inserção da coleção em disciplinas de escolas, aplicação de questionários e capacitação dos professores. Como resultado, foi possível observar um aumento do conhecimento dos professores na capacitação dos temas da coleção em 33,68\%, receptividade e assimilação dos temas pelos alunos em 100,00\%, e interesse pela inserção futura do conteúdo nas disciplinas ministradas em $97,22 \%$. A pesquisa comprovou a utilidade da coleção como meio de cons- 
cientização de educadores e educandos, visando torná-los parceiros e multiplicadores dos temas abordados junto aos seus familiares e comunidade, e posteriormente, incentivando o público em geral a assumir o papel de coparticipação e corresponsabilidade em ações de defesa agropecuária, promovendo a saúde pública e o meio ambiente.

Palavras-chave: Educação Sanitária; Zoonoses; Saúde Pública; Meio ambiente.

ABSTRaCr The objectives of this research were to analyze the knowledge of Elementary School teachers in rural public schools about the content of the "Se Liga Galera" collection, proposed by Secretaria de Estado de Agricultura e Pecuária do Rio de Janeiro (SEAPEC/ $\mathrm{RJ})$, as strategy aimed at agricultural defense, based around policies for the eradication and control of diseases, safe food and pesticides; and to verify the acceptance and perception of these teachers and students about the thematic studied. The study also included a third objective, namely teacher capacitation, so that the contents could be applied in an interdisciplinary manner. The methodology involved the insertion of the collection in schools subjects, the application of questionnaires and the capacitation of teachers. As a result, it was possible to observe an increase in the knowledge of teachers in the capacitation of the themes of the collection of $33.68 \%$, in the receptivity and assimilation of the themes by students of $100.00 \%$, and in interest in the future insertion of the content in the subjects taught of $97.22 \%$. The research proved the usefulness of the collection as a means of increasing the awareness of educators and students, aimed at turning them into partners and multipliers of the themes studied among their relatives and the community, and subsequently encouraging the general public to assume paper of co-participation and co-responsibility in agricultural defense actions, promoting public health and the environment.

Keywords: Sanitary Education; Zoonosis; Public health; EnVIronment.

Resumen Los objetivos de esta investigación fueron analizar el conocimiento de los docentes de educación primaria de escuelas públicas rurales sobre el contenido de la colección "Se Liga Galera", propuesta por la Secretaría de Estado de Agricultura y Ganadería de Río de Janeiro (SEAPEC/RJ), como una estrategia de defensa agricola, basada en políticas de erradicación y control de enfermedades, alimentos inocuos y plaguicidas; y verificar la aceptación y percepción de estos docentes y estudiantes sobre el tema estudiado. El estudio también incluyó un tercer objetivo, a saber, la capacitación de docentes, para que los contenidos pudieran aplicarse de forma interdisciplinaria. La metodología implicó en la inserción de la colección en disciplinas escolares, aplicación de cuestionarios y capacitación docente. Como resultado, fue posible observar un aumento en el conocimiento de los docentes en la capacitación de los temas de la colección en 33,68\%, receptividad y asimilación de temas por estudiantes en 100,00\%, e interés en la futura inserción de contenidos en las disciplinas en 97,22\%. La investigación demostró la utilidad de la colección como un medio de sensibilización de educadores y estudiantes, con el objetivo de hacerlos socios y multiplicadores de los temas abordados con sus familiares y comunidad, y posteriormente, fomentando lo público en general a asumir el papel de coparticipación y corresponsabilidad en las acciones de defensa agrícola, promoviendo la salud pública y el medio ambiente.

Palabras Clave: Educación Sanitaria; Zoonosis; Salud pública; Medio ambiente. 


\section{INTRODUÇÃ̃o}

A Secretaria de Estado de Agricultura e Pecuária do Rio de Janeiro (SEAPEC/RJ) é a instituição oficial de execução das ações de defesa na agropecuária. Tal atribuição é realizada pela Superintendência de Defesa Agropecuária, por meio de suas Coordenadorias, seus sete Órgãos Regionais e seus 27 Núcleos edificados nas diversas regiões do Estado do Rio de Janeiro (SEAPEC/RJ, 2018a).

Esse órgão governamental objetiva controlar e erradicar patologias e pragas em rebanhos e culturas fundamentais para a economia e para a saúde pública do Estado e do país, e cujas ações se realizam por intermédio da gestão e execução de programas nacionais de controle e erradicação de doenças e pragas em animais e vegetais, entre eles: Erradicação e Prevenção da Febre Aftosa; Controle e Erradicação da Brucelose e Tuberculose; Controle da Raiva dos Herbívoros; Controle e Erradicação da Anemia Infecciosa Equina; Sanidade Caprina e Ovina; e, Controle de Resíduos nas Culturas pelo Uso de Agrotóxicos e Pragas Quarentenárias (SEAPEC/RJ, 2018a).

De igual modo, a Secretaria realiza o controle sanitário de animais, vegetais, seus produtos e subprodutos, fiscalização de eventos agropecuários, vigilância zoofitossanitária em propriedades, estabelecimentos agropecuários, fiscalização e inspeção sanitária em indústrias de produtos de origem animal com implantação de "Boas Práticas de Manipulação", registro de estabelecimentos de produtos de origem animal, vigilância epidemiológica, fiscalização do uso de agrotóxicos e destino final de suas embalagens, fiscalização de estabelecimentos que comercializam insumos e educação sanitária.

No ano de 2003, a instituição elaborou o Projeto Educação Sanitária nas escolas rurais (PESER/RJ), com ações educativas específicas para gestores, educadores e educandos, como: palestras, atividades lúdicas, concursos de frases, desenhos, redações, entre outras, para conscientização sobre os vários temas de importância para a agropecuária, meio ambiente e saúde pública (FREITAS; GARCIA, 2012), sempre com o objetivo de ter parceiros nas ações de defesa sanitária animal, vegetal e inspeção de produtos de origem animal.

De 2003 a 2011, participaram do projeto 19.193 alunos e 540 professores de 275 escolas públicas rurais, em 62 municípios. Nesse período, percebeu-se a carência de um material de apoio para educadores e educandos, uma vez que foram criados muitos materiais educativos e de divulgação, mas sempre voltados para um público adulto (FÁ VERO, 2007).

Assim sendo, no ano de 2007 teve início uma longa caminhada para a criação de um material didático, de fácil percepção, que aguçasse a leitura e o aprendizado dos temas, por vezes desconhecidos para educadores e educandos. Nesse sentido, a instituição optou por histórias descritas em quadrinhos (TAVARES; PINHEIRO NETO, 2016), cuja continuidade de cada assunto abordado, bem como, os exercícios de fixação existentes ao final da leitura, objetivavam despertar maior interesse por parte dos alunos. A criação desse material obteve apoio de pedagogos, educadores, médicos veterinários e cartunistas, que enfocaram no desenvolvimento de uma linguagem própria para alunos da faixa etária específica.

Após longos cinco anos de adequações e aprimoramento desse material, foi disponibilizada em 2012 a coleção "Se Liga Galera", que contava como base sete cartilhas, versando sobre os temas: Febre Aftosa, Raiva, Alimentos Seguros, Brucelose, Tuberculose, 
Teníase/Cisticercose e Agrotóxicos (SEAPEC/RJ, 2018b). Dessa forma, iniciaram-se as capacitações de gestores e educadores, com o objetivo de ampliar a capilaridade no interior fluminense e possibilitar uma maior participação e integração desses e de seus alunos na sanidade agropecuária.

A agropecuária depende muito da educação, e sua evolução está atada a uma permanente busca de conhecimentos e informações. Plank (2001, p. 12), autor do livro Política Educacional no Brasil, validou tal pensamento, citando a importância da educação no meio rural, conforme pode ser observado no trecho: “...a relação entre educação e produtividade tem sido corroborada especialmente na agricultura. Pesquisas em vários países têm indicado que produtores rurais com mais escolaridade produzem mais do que aqueles com menos ou nenhuma educação formal".

Nessa direção, um dos principais desafios para o desenvolvimento do país é a qualificação de pessoas e, quanto mais tarde for tratada essa questão, tanto menos resultados surgirão. A ferramenta básica da qualificação é a educação, pois ela torna possível formar profissionais e cidadãos capazes de compreender o ambiente em que vivem e isso permite que se apropriem de conhecimento e poder, possibilitando participação na coletividade e o exercício pleno da cidadania.

Uma das particularidades desta pesquisa está na possibilidade de os docentes ampliarem seus conhecimentos relativos à educação sanitária e repassarem aos seus alunos, gerando como efeito cascata, promoção na qualidade de vida das famílias, principalmente rurais, favorecendo a saúde pública e a segurança alimentar, com o controle da sanidade animal e vegetal e a conservação ambiental, em consonância com o que preceituam as Diretrizes Curriculares Nacionais, Parecer no 4 do Conselho Nacional de Educação/Câmara de Educação Básica (BRASIL, 1998), cujas linhas determinam que assuntos como saúde, educação sanitária, meio ambiente e outros, que influenciem na melhoria da saúde e da qualidade de vida da população, sejam utilizados como temas transversais ou disciplinas complementares nas grades curriculares do Ensino Fundamental.

Justifica-se este estudo por sua relevância social e científica. Socialmente, a investigação contribui para a melhoria da sociedade, para a compreensão do mundo em que vivemos, para o desenvolvimento e emancipação do homem do campo, e para a construção de práticas educativas alternativas, já que os currículos oficiais sempre acabam caindo no ranço neoliberal. Nesse patamar, o material educativo se revela proveitoso à conscientização dos educandos para que se tornem futuros parceiros e multiplicadores dos temas abordados junto aos seus familiares e à comunidade, sensibilizando, dessa forma, o grande público à coparticipação e à corresponsabilidade nas ações de defesa agropecuária, temas esses sim, afetos às suas realidades.

Por sua vez, sua pertinência científica está na contribuição acadêmica dos assuntos debatidos, haja vista levar ao conhecimento do público especializado em educação rural novas ideias para pesquisas de opiniões e/ou atualização de informes. A análise dos argumentos apresentados e a possibilidade de abertura a possíveis reavaliações em função de novas descobertas e, por conseguinte, apresentação de melhores resultados, validam seu préstimo à comunidade científica.

Nesse contexto, o ponto de partida desta investigação procurou responder às questões: será que a proposta de educação sanitária da SEAPEC/RJ, personificada na coleção 
"Se Liga Galera", é bem assimilada por professores do Ensino Fundamental? E como ato contínuo, será que alunos do Ensino Fundamental se interessam e constroem conhecimento a partir dos temas de sanidade agropecuária e de saúde pública dispostos nessa coleção?

Assim, os objetivos desta pesquisa foram analisar o conhecimento de professores do Ensino Fundamental de escolas públicas rurais sobre o conteúdo da coleção "Se Liga Galera”, proposta pela Secretaria de Estado de Agricultura e Pecuária do Rio de Janeiro (SEA$\mathrm{PEC} / \mathrm{RJ}$ ) como atividade estratégica de defesa agropecuária, sobre políticas de erradicação e controle de doenças, alimentos seguros e agrotóxicos; e, verificar a aceitação e percepção de professores e educandos sobre a temática estudada. Para tal fomento, foi necessária ainda a realização de um terceiro objetivo, traduzido na capacitação dos professores do ensino fundamental, para aplicação dos conteúdos de forma interdisciplinar.

\section{Metodologia}

A pesquisa foi desenvolvida no Programa de Pós-Graduação em Educação Agrícola (PPGEA), Instituto de Agronomia, Universidade Federal Rural do Rio de Janeiro (UFRRJ), localizado no município de Seropédica, Estado do Rio de Janeiro, no período de 2013 a 2015.

Caracteriza-se como pesquisa qualiquantitativa, do tipo descritiva e de recorte transversal. Segundo Godoy (1995), na pesquisa qualitativa busca-se estudar e melhor compreender os fenômenos que envolvem os seres humanos e suas relações sociais, sendo esse entendimento determinado por meio da interpretação de seus pensamentos, sentimentos e ações. Fonseca (2002) salientou que a pesquisa quantitativa se centra na objetividade, considerando que a realidade só pode ser compreendida com base na análise de dados brutos, recolhidos com o auxílio de instrumentos padronizados e neutros, recorrendo sempre à linguagem matemática para descrever causas de fenômenos, relações entre variáveis etc. Marconi e Lakatos (2017) definem estudos descritivos como aqueles que visam observar, registrar e descrever as características de determinado fenômeno ocorrido em uma amostra ou população, sem, no entanto, existir uma interação ou envolvimento do pesquisador no assunto analisado. Para Richardson (2018), uma pesquisa de recorte transversal parte de dados coletados em um curto período, com base em uma amostra selecionada para descrever uma população em determinado momento, tal qual agora, fugindo de parâmetros prospectivos e retrospectivos.

Participaram da investigação 36 professores, de ambos os sexos, com idade variando entre 23 a 64 anos, que lecionavam para o quarto e quinto anos do Ensino Fundamental, alguns ministrando disciplinas únicas, e outros disciplinas múltiplas, lotados em 32 escolas públicas rurais dos municípios de Duque de Caxias, Japeri, Maricá, Miracema, Paracambi, Santo Antônio de Pádua e São José do Vale do Rio Preto, todos pertencentes ao Estado do Rio de Janeiro. Fizeram parte também da pesquisa 810 alunos do quarto e quinto anos do Ensino Fundamental das devidas escolas, sob orientação dos referidos professores (Tabela 1). Observa-se aqui que a pesquisa foi efetuada a partir da avaliação dos professores sobre a temática abordada e não dos estudantes. 
Tabela 1: Distribuição dos municípios, e número de escolas, professores e alunos que constituíram o universo da pesquisa.

\begin{tabular}{lccc}
\hline Municípios & Escolas & Professores & Alunos \\
\hline Duque de Caxias & 1 & 1 & 26 \\
Japeri & 5 & 5 & 118 \\
Paracambi & 1 & 1 & 33 \\
Maricá & 10 & 12 & 260 \\
Miracema & 2 & 2 & 60 \\
Santo Antônio de Pádua & 7 & 9 & 136 \\
São José do Vale do Rio Preto & 6 & 6 & 177 \\
\hline Total & 32 & 36 & 810 \\
\hline
\end{tabular}

A escolha pelos municípios deu-se em função da presença de Médicos Veterinários, Engenheiros Agrônomos e Técnicos em Atividades Agropecuárias, pertencentes aos 27 Núcleos da SEAPEC/RJ, que aceitaram participar e fomentar a pesquisa em suas áreas de atuação, e em comum acordo com as Secretarias Municipais de Educação de cada município.

O processo de realização da investigação ocorreu em três momentos, todos realizados no ano de 2014:

\begin{abstract}
No primeiro momento, efetuou-se a apresentação da pesquisa para entendimento dos profissionais pertencentes aos Núcleos da SEAPEC/RJ. O procedimento constou de um encontro para exposição do projeto e do material, e buscou como propósito sensibilizar os profissionais para implantação do mesmo nos municípios sob suas responsabilidades, além do apoio logístico e contatos com as Secretarias Municipais de Educação em suas áreas de atuação. Tais profissionais foram convocados por meio de comunicado interno na SEAPEC/RJ, antes do início do ano letivo.
\end{abstract}

No segundo momento, este dividido em duas etapas, aconteceu a capacitação dos 36 professores, com a presença da pesquisadora e com o auxílio dos profissionais da SEAPEC/RJ, que estabeleceram discussões e dinâmicas de grupo para maior integração dos participantes.

Na primeira etapa, oferecida no primeiro semestre, efetuou-se a apresentação da pesquisa e da coleção "Se Liga Galera", o desenvolvimento das ações elucidativas, e a aplicação presencial de um questionário pré e pós-capacitação, em uma duração de duas horas para respostas. Aqui enfocou-se o conhecimento sobre os temas Febre Aftosa, Raiva e Alimentos Seguros. Ainda nessa etapa, foi fornecida aos educadores a coleção para ser distribuída e trabalhada com seus alunos, CDs contendo as palestras em PDF para consultas e aprimoramento no desenvolvimento dos temas, e a coleção em audiovisual para projeção e visualização em sala de aula.

Na segunda etapa, oferecida no segundo semestre, idêntica à primeira, enfocou-se o conhecimento sobre outros temas, sendo esses, Brucelose, Tuberculose, Teníase/Cisticercose e Agrotóxicos.

O terceiro momento culminou no final do ano letivo, onde aplicou-se aos educadores um questionário presencial, em duração de uma hora para respostas, para análise da cole- 
ção "Se Liga Galera", e verificação da aceitação e percepção dos assuntos dispostos nessa coleção por eles e pelos educandos, interrogando na ocasião sobre o interesse em utilizar o material no ano subsequente e a contribuição desse material didático para o Ensino Fundamental rural.

Todo o processo educativo foi monitorado com visitas periódicas às escolas, palestras para os educadores e educandos e e-mails para dirimir dúvidas e proporcionar maior segurança e apoio às ações de educação. Os educadores inseriram os temas em suas disciplinas, e na busca pela aprendizagem os alunos desenvolveram o assunto elaborando desenhos, redações e jogos. Alguns educadores formularam e aplicaram perguntas sobre os assuntos abordados.

A coleção "Se Liga Galera" é constituída por sete cartilhas, em forma de quadrinhos, que contam histórias diferentes sobre doenças dos animais, a forma de transmissão, sinais clínicos, como prevenir, prejuízos para sanidade animal, saúde pública e meio ambiente; acerca de alimentos seguros, para que alunos e professores saibam a importância dos alimentos inspecionados, as datas de fabricação e de validade; e, a respeito de agrotóxicos, onde se orienta sobre os perigos e cuidados no uso desses defensivos, importância do receituário agronômico, transporte, armazenamento, uso do Equipamento Individual de Proteção (EPI), respeito ao período correto de carência, tríplice lavagem e devolução das embalagens vazias. A coleção dá sempre continuidade a cada assunto abordado, e fornece exercícios lúdicos de fixação ao final da leitura, para despertar maior interesse por parte dos alunos.

Os questionários utilizados nesta pesquisa foram elaborados com perguntas abertas e fechadas. Severino (2007) afirmou que, no primeiro caso, as respostas são escolhidas entre as opções predefinidas pelo pesquisador; e, no segundo, o sujeito pode elaborar as respostas, com suas próprias palavras, a partir de sua percepção pessoal.

O questionário aplicado pré e pós-capacitação, durante o segundo momento, versou acerca das características sociodemográficas dos professores: idade, sexo e grau de estudo; suas práticas docentes: tempo de experiência, proximidade com a vida rural, localização da escola e inserção dos conteúdos relacionados à Educação Sanitária na escola de atuação; seu conhecimento inicial e onde adquirido sobre os temas abordados nas cartilhas; e o seu conhecimento a respeito dos aspectos gerais dos temas, onde foram dispostos os indicadores:

Para a Febre Aftosa: espécies de animais domésticos acometidos; sinais ou sintomas típicos; principais medidas sanitárias; principal meio de prevenção; meses em que devemos vacinar o rebanho; e, local de notificação de casos da doença.

Em relação à Raiva: espécies animais acometidas; principal transmissor para o rebanho e para os humanos; sinais e sintomas em animais; e, o que fazer se uma pessoa tiver contato com animal suspeito.

Quanto aos Alimentos Seguros: cuidados na compra de frango no comércio; no que devemos atentar na compra de ovos, pescados, carnes e embutidos no comércio; quais alimentos deixar por último nas compras em supermercados; o que devemos observar sobre o ambiente e os vendedores; e o que verificar nos rótulos dos produtos.

Referente à Brucelose: espécies acometidas; sinais em humanos infectados; principais vias de transmissão para humanos; ações que o criador deve incrementar para evitar a doença em seu rebanho; ações preventivas para evitar a transmissão para seres humanos; e, providência dos seres humanos caso apresente os sintomas da doença.

Sobre a Tuberculose: espécies acometidas; sinais e sintomas em humanos; vias de 
transmissão para humanos; ações que o criador deve realizar para evitar a doença em seu rebanho; ações preventivas para evitar a transmissão aos seres humanos; e, providências caso os seres humanos apresentem os sintomas.

Relatando sobre a Teníase/Cisticercose: nomes vulgares; via de transmissão da Teníase; via de transmissão da Cisticercose; sintomas da Teníase; e, prevenção para ambas.

Por último, comentando sobre Agrotóxicos: nomes para definir agrotóxicos; como o agricultor deve se proteger durante a preparação e aplicação; como deve ser o local de armazenamento; prejuízos causados ao homem, animal e meio ambiente pelos agrotóxicos e suas embalagens; sintomas de intoxicação pelo ser humano; e, o que fazer com pessoa intoxicada pelo agrotóxico.

O questionário aplicado durante o terceiro momento, aquele em que os educadores avaliaram conclusivamente a aceitação e assimilação dos assuntos dispostos nas cartilhas da coleção "Se Liga Galera", por eles e seus educandos, teve seus indicadores assim formulados: disciplina em que foi inserida a temática; relação das histórias com a realidade do aluno; os alunos são capazes de difundir as noções sobre as doenças, alimentos seguros e agrotóxicos para os familiares e a comunidade; compreensão dos temas pelos alunos; conhecimento inicial dos temas pelos alunos; interesse dos alunos em discutir acerca dos temas; nas reuniões com os familiares e escola houve comentário a respeito do material; os alunos levaram o material para casa; quanto à qualidade das cartilhas; e, você gostaria de continuar utilizando a coleção no próximo ano.

Utilizou-se para tratamento dos dados obtidos por meio das questões abertas a técnica de Análise de Conteúdo, sistematizada por Bardin (2009), que consiste em um conjunto de técnicas de análise das comunicações, visando obter por procedimentos sistemáticos e objetivos de descrição do conteúdo das mensagens, indicadores (quantitativos ou não) que permitam a inferência de conhecimentos relativos às condições de produção/recepção (variáveis inferidas) dessas mensagens.

A Análise de Conteúdo baseia-se em diferentes fases, organizadas em torno de três polos fundamentais, descritos a seguir: 1) pré-análise, etapa que tem como objetivo tornar operacionais e sistematizar as ideias iniciais; 2) exploração do material, etapa em que as respostas obtidas são codificadas e categorizadas; e, 3) tratamento dos resultados (inferência e interpretação), etapa destinada a tornar os resultados significativos e válidos, propondo inferências e realizando interpretações sobre eles.

Todas as informações dos educadores respondentes do questionário foram utilizadas apenas para esta pesquisa, sendo assegurado o sigilo dos participantes, e o consentimento fornecido a partir da assinatura do Termo de Consentimento Livre e Esclarecido (TCLE).

Esta pesquisa foi submetida e aprovada pela Comissão de Ética na Pesquisa (COMEP), da Universidade Federal Rural do Rio de Janeiro, conforme Processo 23083.003286/201501, sendo atestado que a mesma atende aos princípios éticos e está de acordo com a Resolução 466/2012 do Conselho Nacional de Saúde (BRASIL, 2013), que regulamenta os procedimentos de pesquisa envolvendo seres humanos.

\section{RESULTADOS E DISCUSSÃo}

Concernente ao segundo momento, mais precisamente na aplicação do questionário de pré-capacitação, em que se versou acerca das características sociodemográficas dos professores; suas práticas docentes; seu conhecimento inicial e onde foi adquirido sobre os 
temas abordados nas cartilhas; e o seu conhecimento a respeito dos aspectos gerais dos temas; passa-se a seguir a transmitir os dados coletados pelas respostas dos questionados.

Dos 36 professores, apenas um (2,77\%) era do sexo masculino e suas idades variaram de 23 a 64 anos. Em relação ao grau de estudo, 14 (38,88\%) possuíam graduação e 11 (30,55\%) pós-graduação. Quando questionados sobre o contato com a vida rural, 18 (50,00\%) deles responderam positivamente. Quanto ao tempo de experiência em sala de aula, a maioria $(25,00 \%)$ tinha de um a cinco anos. Outra pergunta foi acerca da existência na escola de atuação sobre disciplina que abordasse o tema educação sanitária, e a minoria (16,66\%) dos educadores respondeu que sim e que inseriam a educação sanitária nas aulas de Ciências. A maior parte das escolas onde os participantes atuavam era rural, em número de 20 (55,55\%) (Tabela 2).

Tabela 2: Dados relacionados aos 36 professores participantes da pesquisa, relatados no questionário pré-capacitação, em seus indicadores: características sociodemográficas, práticas docentes e proximidade com a vida rural.

\begin{tabular}{|c|c|c|}
\hline Indicadores & Número & Percentual (\%) \\
\hline $\begin{array}{l}\text { Sexo } \\
\text { Masculino } \\
\text { Feminino }\end{array}$ & $\begin{array}{c}1 \\
35\end{array}$ & $\begin{array}{c}2,77 \\
97,22\end{array}$ \\
\hline $\begin{array}{l}\text { Idade } \\
\leq 30 \text { anos } \\
31 \text { a } 40 \text { anos } \\
41 \text { a } 50 \text { anos } \\
51 \text { a } 60 \text { anos } \\
61 \text { a } 70 \text { anos } \\
\geq 70 \text { anos }\end{array}$ & $\begin{array}{c}9 \\
14 \\
8 \\
3 \\
2 \\
0\end{array}$ & $\begin{array}{c}25,00 \\
38,88 \\
22,22 \\
8,33 \\
5,55 \\
0,00\end{array}$ \\
\hline $\begin{array}{l}\text { Grau de estudo } \\
\text { Pós-graduação } \\
\text { Graduação } \\
\text { Ensino Médio }\end{array}$ & $\begin{array}{l}11 \\
14 \\
11\end{array}$ & $\begin{array}{l}30,55 \\
38,88 \\
30,55\end{array}$ \\
\hline $\begin{array}{l}\text { Experiência em sala de aula } \\
\leq 5 \text { anos } \\
6 \text { a } 10 \text { anos } \\
11 \text { a } 15 \text { anos } \\
16 \text { a } 20 \text { anos } \\
21 \text { a } 25 \text { anos } \\
26 \text { a } 30 \text { anos } \\
\geq 31 \text { anos } \\
\text { Sem respostas }\end{array}$ & $\begin{array}{l}9 \\
6 \\
4 \\
5 \\
7 \\
3 \\
0 \\
2\end{array}$ & $\begin{array}{c}25,00 \\
16,66 \\
11,11 \\
13,88 \\
19,44 \\
8,33 \\
0,00 \\
5,55\end{array}$ \\
\hline $\begin{array}{l}\text { Disciplina na escola abordando o tema educação sanitária } \\
\text { Sim } \\
\text { Não }\end{array}$ & $\begin{array}{c}6 \\
30\end{array}$ & $\begin{array}{l}16,66 \\
83,33\end{array}$ \\
\hline $\begin{array}{l}\text { Em quais disciplinas inseriram o tema educação sanitária } \\
\text { Ciências }\end{array}$ & 6 & 16,67 \\
\hline $\begin{array}{l}\text { Localização da escola de atuação } \\
\text { Rural } \\
\text { Urbana }\end{array}$ & $\begin{array}{l}20 \\
16\end{array}$ & $\begin{array}{l}55,55 \\
44,44\end{array}$ \\
\hline $\begin{array}{l}\text { Contato com a vida rural } \\
\text { Sim } \\
\text { Não } \\
\text { Eventualmente } \\
\text { Sem respostas }\end{array}$ & $\begin{array}{c}18 \\
4 \\
13 \\
1\end{array}$ & $\begin{array}{c}50,00 \\
11,11 \\
36,11 \\
2,77\end{array}$ \\
\hline
\end{tabular}


Nas questões efetuadas sobre o conhecimento inicial dos temas, grande parte dos professores respondeu positivamente. Sobre a Febre Aftosa, 19 (52,77\%) afirmaram que já conheciam; Raiva, 26 (72,22\%); Alimentos Seguros, 13 (36,11\%); Tuberculose, 24 (66,66\%); Teníase, 14 (38,88\%); e, Agrotóxicos, 22 (61,11\%). Quanto às doenças Brucelose e Cisticercose, apenas $9(25,00 \%)$ e $5(13,88 \%)$, respectivamente, disseram ter algum conhecimento. A maioria dos respondentes informou ter um conhecimento básico obtido por meio da mídia (Tabelas 3 e 4).

Tabela 3: Distribuição percentual do conhecimento inicial sobre os temas apresentados nas cartilhas da coleção "Se Liga Galera", relatados no questionário pré-capacitação pelos 36 professores participantes da pesquisa.

\section{Conhecimento inicial}

\begin{tabular}{lcccccccc}
\cline { 2 - 8 } Temas & \multicolumn{2}{c}{ Sim } & \multicolumn{2}{c}{ Não } & \multicolumn{2}{c}{ Só ouviu falar } & \multicolumn{2}{c}{ Não Respondeu } \\
\cline { 2 - 8 } & $\mathbf{N}$ & $\mathbf{\%}$ & $\mathbf{N}$ & $\mathbf{\%}$ & $\mathbf{N}$ & $\mathbf{\%}$ & $\mathbf{N}$ & \% \\
\hline Febre Aftosa & 19 & 52,77 & 0 & 0,00 & 17 & 47,22 & 0 & 0,00 \\
Raiva & 26 & 72,22 & 0 & 0,00 & 9 & 25,00 & 1 & 2,77 \\
Alimentos Seguros & 13 & 36,11 & 9 & 25,00 & 11 & 30,55 & 3 & 8,33 \\
Brucelose & 9 & 25,00 & 11 & 30,55 & 13 & 36,11 & 3 & 8,33 \\
Tuberculose & 24 & 66,66 & 0 & 0,00 & 6 & 16,66 & 6 & 16,66 \\
Teníase & 14 & 38,88 & 3 & 8,33 & 12 & 33,33 & 7 & 19,44 \\
Cisticercose & 5 & 13,88 & 16 & 44,44 & 6 & 16,66 & 9 & 25,00 \\
Agrotóxicos & 22 & 61,11 & 2 & 5,55 & 3 & 8,33 & 9 & 25,00 \\
\hline
\end{tabular}

Tabela 4: Distribuição percentual dos meios pelos quais os temas apresentados nas cartilhas da coleção "Se Liga Galera" foram conhecidos, relatados no questionário pré-capacitação pelos 36 professores participantes da pesquisa.

\begin{tabular}{|c|c|c|c|c|c|c|c|c|c|c|c|c|}
\hline \multirow{3}{*}{ Temas } & \multicolumn{12}{|c|}{ Como os temas foram conhecidos } \\
\hline & \multicolumn{2}{|c|}{ Mídia } & \multicolumn{2}{|c|}{ Fazenda } & \multicolumn{2}{|c|}{ Família } & \multicolumn{2}{|c|}{ Amigos } & \multicolumn{2}{|c|}{ Escola } & \multicolumn{2}{|c|}{$\begin{array}{c}\text { Não } \\
\text { respondeu }\end{array}$} \\
\hline & $\mathrm{N}$ & $\%$ & $\mathrm{~N}$ & $\%$ & $\mathrm{~N}$ & $\%$ & $\mathrm{~N}$ & $\%$ & $\mathrm{~N}$ & $\%$ & $\mathrm{~N}$ & $\%$ \\
\hline Febre Aftosa & 11 & 30,55 & 4 & 11,11 & 2 & 5,55 & 2 & 5,55 & 0 & 0,00 & 17 & 47,22 \\
\hline Raiva & 15 & 41,66 & 6 & 16,66 & 5 & 13,88 & 0 & 0,00 & 0 & 0,00 & 10 & 27,77 \\
\hline Alimentos Seguros & 10 & 27,77 & 0 & 0,00 & 0 & 0,00 & 0 & 0,00 & 0 & 0,00 & 26 & 72,22 \\
\hline Brucelose & 3 & 8,33 & 0 & 0,00 & 0 & 0,00 & 1 & 2,77 & 0 & 0,00 & 32 & 88,88 \\
\hline Tuberculose & 11 & 30,55 & 0 & 0,00 & 4 & 11,11 & 4 & 11,11 & 1 & 2,77 & 16 & 44,44 \\
\hline Teníase & 8 & 22,22 & 0 & 0,00 & 0 & 0,00 & 0 & 0,00 & 0 & 0,00 & 28 & 77,77 \\
\hline Cisticercose & 3 & 8,33 & 0 & 0,00 & 0 & 0,00 & 1 & 2,77 & 0 & 0,00 & 32 & 88,88 \\
\hline Agrotóxicos & 16 & 44,44 & 0 & 0,00 & 0 & 0,00 & 1 & 2,77 & 0 & 0,00 & 19 & 52,77 \\
\hline
\end{tabular}

Verificou-se nas respostas que os professores possuíam conhecimento inicial sobre alguns temas, a exemplo: Febre Aftosa, Raiva, Tuberculose e Agrotóxicos. Os maiores 
percentuais de conhecimento inicial foram para a Raiva, doença endêmica em nosso Estado, e para a Tuberculose, doença que já matou e continua matando muitas pessoas e animais (HIJJAR, 2005; OLIVEIRA et al., 2010; MOUTINHO et al., 2015). Quanto ao conhecimento acerca dos temas Brucelose, Teníase, Cisticercose e Alimentos Seguros, o percentual foi baixo, demonstrando dessa forma um desconhecimento dessas doenças por parte da maioria dos educadores.

Essas perguntas do pré-questionário acerca do conhecimento inicial sobre as doenças, alimentos seguros e agrotóxicos, antes da capacitação, foram essenciais para a análise da pesquisa. Pode-se observar o quanto se faz necessário proporcionar aos educadores de escolas rurais uma contínua capacitação a respeito dos assuntos relevantes para a sanidade animal, vegetal, para a saúde pública e o meio ambiente, dessa forma poderá ocorrer uma maior interação e integração de educadores na vivência com seus educandos no dia a dia em uma escola rural.

A seguir, também nesse questionário pré-capacitação, os docentes responderam às questões que versavam sobre aspectos gerais dos temas, e que tinham as respostas certas e erradas predeterminadas numa lista de opções (Tabela 5). Infere-se aqui que o cálculo da determinação da frequência percentual de respostas corretas foi realizado considerando as opções escolhidas e não do número de respondentes.

Para a Febre Aftosa, os índices médios de acertos foram: espécies de animais domésticos acometidos $(53,47 \%)$; sinais ou sintomas típicos $(39,81 \%)$; principais medidas sanitárias (75,00\%); principal meio de prevenção (77,77\%); meses em que devemos vacinar o rebanho (30,55\%); e, local de notificação de casos da doença $(13,88 \%)$.

Em relação à Raiva, os índices médios de acertos foram: espécies animais acometidas $(33,88 \%)$; principal transmissor para o rebanho $(58,33 \%)$ e para os humanos $(27,77 \%)$; sinais e sintomas em animais $(25,69 \%)$; e, o que fazer se uma pessoa tiver contato com animal suspeito $(25,00 \%)$.

Quanto aos Alimentos Seguros, os índices médios foram: cuidados na compra de frango no comércio $(84,02 \%)$; no que devemos atentar na compra de ovos $(79,44 \%)$, pescados $(48,03 \%)$ e carnes e embutidos $(36,00 \%)$ no comércio; quais alimentos deixar por último nas compras em supermercados $(83,33 \%)$; o que devemos observar sobre o ambiente e os vendedores (74,30\%); e, o que verificar nos rótulos dos produtos $(71,29 \%)$.

Referente à Brucelose, os índices médios de acertos ficaram assim definidos: espécies acometidas $(62,22 \%)$; sinais em humanos infectados $(39,19 \%)$; principais vias de transmissão para humanos $(32,63 \%)$; ações que o criador deve incrementar para evitar a doença em seu rebanho $(69,44 \%)$; ações preventivas para evitar a transmissão para seres humanos $(57,63 \%)$; e, providência dos seres humanos caso apresente os sintomas da doença $(72,22 \%)$. 
Tabela 5: Percentual médio de acertos das respostas dos questionários pré e pós-capacitação dos 36 professores, relacionado ao conhecimento dos aspectos gerais dos temas das cartilhas da coleção "Se Liga Galera", e percentual médio do ganho de conhecimento.

\begin{tabular}{|c|c|c|c|}
\hline Temas & $\begin{array}{l}\text { Acerto médio da } \\
\text { pré-capacitação } \\
(\%)\end{array}$ & $\begin{array}{l}\text { Acerto médio } \\
\text { da pós- } \\
\text { capacitação } \\
(\%)\end{array}$ & $\begin{array}{c}\text { Ganho de } \\
\text { conhecimento } \\
\text { médio }(\%)\end{array}$ \\
\hline $\begin{array}{l}\text { Febre Aftosa } \\
\text { Espécies animais acometidas } \\
\text { Sinais ou sintomas típicos } \\
\text { Principais medidas sanitárias } \\
\text { Principal meio de prevenção } \\
\text { Meses de vacinação do rebanho } \\
\text { Local de notificação de casos da doença }\end{array}$ & $\begin{array}{l}53,47 \\
39,81 \\
75,00 \\
77,77 \\
30,55 \\
13,88\end{array}$ & $\begin{array}{l}84,02 \\
98,14 \\
95,55 \\
97,22 \\
97,22 \\
83,33\end{array}$ & $\begin{array}{l}30,55 \\
58,33 \\
20,55 \\
19,45 \\
66,67 \\
69,48\end{array}$ \\
\hline $\begin{array}{l}\text { Raiva } \\
\text { Espécies animais acometidas } \\
\text { Principal transmissor para o rebanho } \\
\text { Principal transmissor para humanos } \\
\text { Sinais e sintomas animais } \\
\text { Contato humano com animal suspeito }\end{array}$ & $\begin{array}{l}33,88 \\
58,33 \\
27,77 \\
25,69 \\
25,00\end{array}$ & $\begin{array}{c}78,05 \\
97,22 \\
100,00 \\
86,80 \\
83.33\end{array}$ & $\begin{array}{l}44,17 \\
38,89 \\
72,23 \\
61,11 \\
58,33\end{array}$ \\
\hline $\begin{array}{l}\text { Alimentos seguros } \\
\text { Cuidados na compra de frango } \\
\text { O que observar na compra de ovos } \\
\text { O que observar na compra de pescados } \\
\text { O que observar na compra de carnes/ } \\
\text { embutidos } \\
\text { Alimentos deixados por último na compra } \\
\text { O que observar sobre o ambiente e } \\
\text { vendedores } \\
\text { O que observar no rótulo dos produtos }\end{array}$ & $\begin{array}{l}84,02 \\
79,44 \\
48,03 \\
36,00 \\
83,33 \\
74,30 \\
71,29\end{array}$ & $\begin{array}{l}100,00 \\
98,33 \\
99,07 \\
95,83 \\
97.22 \\
94,44 \\
97,22\end{array}$ & $\begin{array}{l}15,98 \\
18,89 \\
51,04 \\
59,83 \\
13,89 \\
20,14 \\
25,93\end{array}$ \\
\hline $\begin{array}{l}\text { Brucelose } \\
\text { Espécies acometidas } \\
\text { Sinais em humanos infectados } \\
\text { Principais vias de transmissão para } \\
\text { humanos } \\
\text { Ações para evitar doença no rebanho } \\
\text { Ações para evitar transmissão para } \\
\text { humanos } \\
\text { Providência caso apresente sintomas/ } \\
\text { humanos }\end{array}$ & $\begin{array}{l}62,22 \\
39,19 \\
32,63 \\
69,44 \\
57,63 \\
72,22\end{array}$ & $\begin{array}{c}91,11 \\
77,77 \\
88,88 \\
99,30 \\
97,22 \\
100,00\end{array}$ & $\begin{array}{l}28,89 \\
38,58 \\
56,25 \\
29,86 \\
39,59 \\
27,78\end{array}$ \\
\hline
\end{tabular}




\begin{tabular}{lccc}
\hline Temas & $\begin{array}{c}\text { Acerto médio da } \\
\text { pré-capacitação } \\
(\%)\end{array}$ & $\begin{array}{c}\text { Acerto médio } \\
\text { da pós- } \\
\text { capacitação } \\
(\%)\end{array}$ & $\begin{array}{c}\text { Ganho de } \\
\text { conhecimento } \\
\text { médio (\%) }\end{array}$ \\
\hline Tuberculose & 62,77 & 91,11 & 28,34 \\
Espécies acometidas & 80,55 & 97,91 & 17,36 \\
Sinais e sintomas humanos & 62,03 & 96,29 & 34,26 \\
Vias de transmissão para humanos & 50,69 & 81,25 & 30,56 \\
Ações para evitar doença no rebanho & 59,72 & 97,22 & 37,50 \\
Ações para evitar transmissão para & 100,00 & 100,00 & 0,00 \\
humanos & & & \\
Providência caso apresente sintomas/ & & & \\
humanos & & 94,44 & 38,89 \\
\hline Teníase/Cisticercose & 55,55 & 91,66 & 58,33 \\
Nome vulgar da Teníase & 33,33 & 100,00 & 11,12 \\
Nome vulgar da Cisticercose & 88,88 & 100,00 & 27,78 \\
Via de transmissão da Teníase & 72,22 & 70,83 & 26,04 \\
Via de transmissão da Cisticercose & 44,79 & 98,61 & 9,73 \\
Sintomas da Teníase & 88,88 & & \\
Prevenção para ambas & & 97,91 & 24,30 \\
\hline Agrotóxicos & 73,61 & 100,00 & 19,45 \\
Nomes para definir agrotóxicos & 80,55 & 100,00 & 11,12 \\
Proteção durante a preparação e aplicação & 88,88 & 98,33 & 15,56 \\
Local de armazenamento & 82,77 & 93,33 & 15,56 \\
Prejuízos ao homem, animal e meio & 77,77 & 100,00 & 16,67 \\
ambiente & 83,33 & & \\
Sintomas de intoxicação pelo ser humano & & & \\
O que fazer com a pessoa intoxicada & & & \\
\hline
\end{tabular}

Sobre a Tuberculose, os índices médios de acertos demonstraram: espécies acometidas $(62,77 \%)$; sinais e sintomas em humanos (80,55\%); vias de transmissão para humanos (62,03\%); ações que o criador deve realizar para evitar a doença em seu rebanho $(50,69 \%)$; ações preventivas para evitar a transmissão aos seres humanos (59,72\%); e, providências caso os seres humanos apresentem os sintomas $(100,00 \%)$.

Comentando sobre a Teníase/Cisticercose, os índices médios de acertos foram: nome vulgar da Teníase $(55,55 \%)$ e da Cisticercose (33,33\%); via de transmissão da Teníase (88,88\%); via de transmissão da Cisticercose (72,22\%); sintomas da Teníase $(44,79 \%)$; prevenção para ambas $(88,88 \%)$.

Por último, sobre Agrotóxicos, ficaram assim estabelecidos os índices médios de acertos: nomes para definir agrotóxicos $(73,61 \%)$; como o agricultor deve se proteger durante a preparação e aplicação $(80,55 \%)$; como deve ser o local de armazenamento $(88,88 \%)$; prejuízos causados ao homem, animal e meio ambiente pelos agrotóxicos e suas embalagens $(82,77 \%)$; sintomas de intoxicação pelo ser humano (77,77\%); e, o que fazer com a pessoa intoxicada pelo agrotóxico $(83,33 \%)$.

Após o período de capacitação dos professores, ocorrido ainda nesse segundo momento, ou seja, depois da aplicação das ações elucidativas sobre os temas contidos nas cartilhas da coleção "Se Liga Galera", em que se desenvolveram discussões e dinâmicas, 
apresentação de palestras, multimídia etc., com a presença da pesquisadora e profissionais da SEAPEC/RJ, foi novamente ofertado o mesmo questionário pré-capacitação para os professores, no intuito de levantar o quão significativo foi o aprendizado adquirido.

Os índices médios de acertos referentes às respostas sobre os temas estudados pós-capacitação encontram-se dispostos na Tabela 5. Novamente infere-se que o cálculo da determinação da frequência percentual de respostas corretas foi realizado considerando as opções escolhidas e não do número de respondentes.

Quanto à Febre Aftosa, os índices médios assim ficaram: espécies de animais domésticos acometidos (84,02\%); sinais ou sintomas típicos $(98,14 \%)$; principais medidas sanitárias $(95,55 \%)$; principal meio de prevenção $(97,22 \%)$; meses em que devemos vacinar o rebanho (97,22\%); e, local de notificação de casos da doença (83,33\%).

Sobre a Raiva, os índices médios de acertos foram: espécies animais acometidas (78,05\%); principal transmissor para o rebanho $(97,22 \%)$ e para os humanos $(100,00 \%)$; sinais e sintomas em animais $(86,80 \%)$; e, o que fazer se uma pessoa tiver contato com animal suspeito $(83,33 \%)$.

Em relação aos Alimentos Seguros, os índices médios foram: cuidados na compra de frango no comércio (100,00\%); no que devemos atentar na compra de ovos $(98,33 \%)$, pescados $(99,07 \%)$ e carnes e embutidos $(95,83 \%)$ no comércio; quais alimentos deixar por último nas compras em supermercados $(97,22 \%)$; o que devemos observar sobre o ambiente e os vendedores (94,44\%); e, o que verificar nos rótulos dos produtos $(97,22 \%)$.

Para a Brucelose, os índices médios de acertos foram assim estabelecidos: espécies acometidas $(91,11 \%)$; sinais em humanos infectados $(77,77 \%)$; principais vias de transmissão para humanos $(88,88 \%)$; ações que o criador deve incrementar para evitar a doença em seu rebanho (99,30\%); ações preventivas para evitar a transmissão para seres humanos $(97,22 \%)$; e, providência dos seres humanos caso apresente os sintomas da doença $(100,00 \%)$.

Relatando sobre a Tuberculose, os índices médios de acertos demonstraram: espécies acometidas $(91,11 \%)$; sinais e sintomas em humanos (97,91\%); vias de transmissão para humanos (96,29\%); ações que o criador deve realizar para evitar a doença em seu rebanho $(81,25 \%)$; ações preventivas para evitar a transmissão aos seres humanos $(97,22 \%)$; e, providências caso os seres humanos apresentem os sintomas (100,00\%).

Sobre a Teníase/Cisticercose, os índices médios de acertos foram: nome vulgar da Teníase (94,44\%) e da Cisticercose (91,66\%); via de transmissão da Teníase $(100,00 \%)$; via de transmissão da Cisticercose (100,00\%); sintomas da Teníase (70,83\%); e, prevenção para ambas $(98,61 \%)$.

Terminando, sobre Agrotóxicos, foram assim definidos os índices médios de acertos: nomes para definir agrotóxicos $(97,91 \%)$; como o agricultor deve se proteger durante a preparação e aplicação (100,00\%); como deve ser o local de armazenamento $(100,00 \%)$; prejuízos causados ao homem, animal e meio ambiente pelos agrotóxicos e suas embalagens $(98,33 \%)$; sintomas de intoxicação pelo ser humano (93,33\%); e, o que fazer com a pessoa intoxicada pelo agrotóxico $(100,00 \%)$.

Após análise dos questionários pré e pós-capacitação, pode-se chegar a algumas elucidações (Tabelas 5 e 6 ). 
Concernente ao tema Febre Aftosa, percebeu-se a eficiência da capacitação, quando ao final, na aplicação do questionário pós-capacitação, foram contabilizados valores médios do ganho de conhecimento acima de $60,00 \%$, como foi o caso do ganho na questão "Local de notificação de casos da doença" (69,48\%) e "Meses de vacinação do rebanho" $(66,67 \%)$. Nesse tema, houve um aumento médio total do ganho de conhecimento no valor de $44,17 \%$. De acordo com o percentual médio de acertos das respostas do questionário pré-capacitação $(48,41 \%)$, ficou entendido que era mediano o conhecimento dos professores a respeito do tema em questão, o que está em conformidade com o número de professores que alegaram afirmativamente um conhecimento inicial.

Tabela 6: Percentual médio total e geral de acertos das respostas dos questionários pré e pós-capacitação dos educadores, relacionado aos temas ofertados nas cartilhas da coleção "Se Liga Galera", e percentual médio total e geral do ganho de conhecimento.

\begin{tabular}{lccc}
\hline Temas & $\begin{array}{c}\text { Acerto médio } \\
\text { total da pré- } \\
\text { capacitação } \\
(\mathbf{\%})\end{array}$ & $\begin{array}{c}\text { Acerto médio } \\
\text { total da pós- } \\
\text { capacitação } \\
\mathbf{( \% )}\end{array}$ & $\begin{array}{c}\text { Ganho de } \\
\text { conhecimento médio } \\
\text { total (\%) }\end{array}$ \\
\hline Febre Aftosa & 48,41 & 92,58 & 44,17 \\
Raiva & 34,13 & 89,08 & 54.95 \\
Alimentos Seguros & 68,05 & 97.44 & 29,39 \\
Brucelose & 55,55 & 92,38 & 36,83 \\
Tuberculose & 69,29 & 93,96 & 24,67 \\
Teníase/Cisticercose & 63,94 & 92,59 & 28,65 \\
Agrotóxicos & 81,15 & 98,26 & 17,11 \\
\hline Média geral de acertos por & & & 33,68 \\
fases de capacitação e por & 60,07 & 93,75 & \\
ganho de conhecimento $(\%)$ & & & \\
\hline
\end{tabular}

Já sobre o tema Raiva, existiu um aumento médio total do ganho de conhecimento de $54,95 \%$. Esse foi o tema em que mais ganho de conhecimento se verificou, traduzido principalmente quando das questões "Principal transmissor da doença para humanos" e "Sinais e sintomas nos animais", com percentuais médios de ganho pós-capacitação de 72,23\% e $61,11 \%$, respectivamente. Certamente, podemos inferir ao final desta análise que a doença Raiva era a menos conhecida pelos professores, demonstrando uma contradição ao mencionado pela maioria, quando da investigação acerca do conhecimento inicial dos temas, em que $26(72,22 \%)$ afirmaram já possuir um conhecimento prévio e elencarem a doença como a de maior conhecimento inicial.

Com relação ao tema Alimentos Seguros, observou-se já na aplicação do questionário pré-capacitação um conhecimento sobre os aspectos gerais bem elevado pelos professores, isso traduzido no acerto das questões pela maioria, como exemplo "Cuidados na compra de frango" e "Alimentos deixados por último na compra", com valores médios de 84,02\% e $83,33 \%$, respectivamente. Nesse tema, houve um acerto total médio no questionário pré- 
-capacitação de $68,05 \%$ e do questionário pós-capacitação de 97,44\%. Houve, então, um ganho de conhecimento total médio de $29,39 \%$. Aqui também existiu uma contradição ao relatado pelos professores sobre um conhecimento inicial, onde apenas $13(36,11 \%)$ afirmaram possuir uma percepção prévia a respeito do tema, o que não se justificou pelo alto acerto nas respostas de ambos os questionários.

A respeito do tema Brucelose houve um ganho de conhecimento médio total no valor de $36,83 \%$. Nesse tema, o menor entendimento no questionário pré-capacitação foi sobre as "Principais vias de transmissão para humanos" (32,63\%) e "Sinais em humanos infectados" (39,19\%), o que ficou sanado após a capacitação quando das respostas para as mesmas questões, com valores médios de acertos em 88,88\% e 77,77\%, respectivamente. Enquanto no questionário pré-capacitação ocorreu um acerto médio total das respostas em $55,55 \%$, no pós sucedeu um acerto de $92,38 \%$. Quando inferidos sobre um conhecimento inicial a respeito do tema, apenas nove $(25,00 \%)$ dos professores afirmaram ter algum conhecimento, o que denota certa equivalência com as respostas elencadas no questionário pré-capacitação acerca dos aspectos gerais da doença.

A respeito da Tuberculose, os valores de acertos médios totais das respostas ficaram em $69,29 \%$ para o questionário pré-capacitação, e de $93,96 \%$ para o questionário pós-capacitação. Já nas respostas acerca do conhecimento inicial, os professores relataram possuir certo entendimento sobre essa doença, quando a maioria $(66,66 \%)$ respondeu afirmativamente. Houve ao final da capacitação um ganho de conhecimento médio total de $24,67 \%$, índice bem inferior quando comparado aos valores observados entre os outros temas. Esse foi um dos temas mais conhecidos pelos professores, o que ficou demonstrado ao final, pela pequena taxa de aquisição de conhecimento sobre o assunto.

Quanto ao tema Teníase/Cisticercose, observou-se ao final da capacitação um ganho de conhecimento médio total de $28,65 \%$. Aqui, o percentual médio total de respostas corretas foi de $63,94 \%$ no questionário pré-capacitação e de $92,59 \%$ no questionário pós-capacitação. O menor entendimento sobre as doenças foi demonstrado nas perguntas referentes aos nomes vulgares, com valores totais médios de ganho de conhecimento nessas questões em $38,89 \%$ e $58,33 \%$, respectivamente. Nesse tema, ficou confirmado o não conhecimento inicial relatado pelos professores $(13,88 \%)$ a respeito da doença Cisticercose.

Por último, relatando sobre Agrotóxicos, contabilizou-se um ganho de conhecimento médio total de $17,11 \%$. Sem dúvida alguma, esse foi o tema mais conhecido pelos professores, que desde o princípio confirmaram um conhecimento inicial de $61,11 \%$. Tal conhecimento já era percebido quando do número médio de acertos das questões do questionário pré-capacitação, por exemplo: "Prejuízos ao homem, animal e meio ambiente" e "Local correto para armazenamento", em que os professores acertaram $82,77 \%$ e $88,88 \%$ das respostas, respectivamente. Nesse questionário pré-capacitação existiu um número de acertos médios totais das respostas de $81,15 \%$, próximo aos do pós-capacitação que ficou em $98,26 \%$.

Acredita-se que o maior conhecimento sobre Agrotóxicos é oriundo do ensino desse tema na escola, visto que é um tópico dos conteúdos de Ciências do quarto e quinto anos do Ensino Fundamental (primeiro segmento), alvos desta pesquisa, e que o ensino do assunto ano a ano estabeleceu uma grande percepção acerca do tema pelos professores (MINISTÉRIO DA EDUCAÇÃO, 2006). Apesar de os professores terem mencionado a aquisição do conhecimento inicial pela mídia, considera-se ainda mais que esse veio dos conteúdos de Ciências ministrados por eles no seu cotidiano nas escolas. Nota-se mais adiante, no ques- 
tionário de avaliação dos professores (terceiro momento), que o tema foi inserido pelos professores nos conteúdos de Ciências de 31 escolas participantes desta pesquisa.

Acerca do tema Alimentos Seguros, em que se observou um grande número de acertos nas questões sobre os aspectos gerais, tanto no questionário pré quanto pós-capacitação, deve-se cogitar como explicação a mesma já mencionada, visto que esse tópico faz parte igualmente dos conteúdos de Ciências aplicada no segmento alvo (MINISTÉRIO DA EDUCAÇÃO, 2006). Ressalta-se um não entendimento a respeito das respostas sobre o pouco conhecimento inicial relatado pelos questionados, já que os mesmos foram muito bem nas questões sobre os aspectos gerais.

Concernente ao tema Raiva, em que $72,22 \%$ afirmaram possuir um conhecimento inicial, o que mais tarde foi rejeitado, pelo baixo número de acertos sobre os aspectos gerais da doença, e comentando até mesmo acerca de outras doenças citadas na coleção "Se Liga Galera", o baixo índice de conhecimento dos aspectos gerais é mencionado na literatura, como devido à ineficiente capacitação do professor em sua formação acadêmica quando do tema educação em saúde, e também da percepção de muitos professores de que a responsabilidade sobre tais temas seria exclusivamente de professores de Ciências e Biologia (LEONELLO; L'ABBATE, 2006; MARQUES, 2007; FRAGA et al., 2009). Nesta pesquisa, entendeu-se o conhecimento inicial oriundo da mídia, citado para todos os temas sobre doenças, como algo muito superficial, sem maiores aprofundamentos. E como a maioria dos professores questionados leciona Ciências, parte-se do entendimento da existência de lacunas em suas formações acerca da doença, por conseguinte da não difusão dos conhecimentos para seus alunos, e assim, da não assimilação por parte deles do assunto. Uchôa et al. (2004) relataram que na prática o que se observa é que a maior parte dos estudantes de pedagogia não recebe formação para o trabalho com saúde, especialmente quando se trata de zoonoses.

O tema Tuberculose, que teve relatado grande conhecimento inicial e índices elevados de conhecimentos sobre os aspectos gerais, tanto na fase pré quanto pós-capacitação, parece possuir sua percepção provinda não só da mídia como mencionado, mas também pelas discussões entre familiares e amigos (Tabelas 3 e 4). De modo diferente do relatado a respeito da doença Raiva, que também era um tema bastante discutido por familiares, aqui existia um conhecimento sólido. Sánchez e Bertolozzi (2004), concordando com nossa opinião, observaram em seus estudos com estudantes universitários que o conhecimento sobre Tuberculose era provindo de instituições de ensino, como faculdade, colegial e curso preparatório para o vestibular (25,5\%), mídia (14,1\%) e familiares (9,5\%). Maia et al. (2017), trabalhando com alunos do terceiro ano do Ensino Médio, relataram que o conhecimento dos mesmos acerca da doença era bem evidente, sendo esse adquirido em maiores percentuais por intermédio da televisão $(46,4 \%)$ e da escola $(17,1 \%)$.

Em que pese algumas contradições, baixas ou altas taxas de assimilação, fica explícito o incremento do conhecimento dos temas pelos professores da coleção "Se Liga Galera", quando no somatório de todas as percentagens foi contabilizado $33,68 \%$ de ganho de conhecimento médio geral, dando mérito à empreitada na concretização do objetivo "capacitação de professores do ensino fundamental, para aplicação dos conteúdos de forma interdisciplinar".

No terceiro momento dessa pesquisa foi encaminhado aos 36 professores participantes um questionário que visou uma avaliação por parte desses educadores, sobre a aceitação e assimilação dos assuntos dispostos nas cartilhas da coleção "Se Liga Galera", por eles e seus educandos. Com relação às respostas dos indicadores selecionados para tal apuração, ficou assim definido (Tabela 7): 
Tabela 7: Indicadores direcionados à avaliação dos educadores sobre a aceitação e percepção dos assuntos dispostos nas cartilhas da coleção "Se Liga Galera", por eles e seus educandos.

\begin{tabular}{|c|c|c|}
\hline Indicadores & Número & $\begin{array}{c}\text { Percentual } \\
(\%)\end{array}$ \\
\hline \multicolumn{3}{|c|}{ Disciplina em que foi inserida a temática (em número de escolas) } \\
\hline Ciências & 31 & 86,11 \\
\hline Artes & 20 & 55,55 \\
\hline Português & 18 & 50,00 \\
\hline Matemática & 11 & 30,55 \\
\hline Geografia & 9 & 25,00 \\
\hline História & 8 & 22,22 \\
\hline \multicolumn{3}{|c|}{ Relação das histórias com a realidade do aluno } \\
\hline $\operatorname{Sim}$ & 36 & 100,00 \\
\hline Não & 0 & 0,00 \\
\hline \multicolumn{3}{|c|}{ Alunos conseguem difundir os temas para familiares e } \\
\hline Sim & 36 & 100,00 \\
\hline Não & 0 & 0,00 \\
\hline \multicolumn{3}{|c|}{ Compreensão dos temas pelos alunos } \\
\hline $\operatorname{Sim}$ & 36 & 100,00 \\
\hline Não & 0 & 0,00 \\
\hline \multicolumn{3}{|c|}{ Conhecimento inicial dos temas pelos alunos } \\
\hline $\operatorname{Sim}$ & 36 & 100,00 \\
\hline Não & 0 & 0,00 \\
\hline \multicolumn{3}{|c|}{ Interesse dos alunos em discutir sobre os temas } \\
\hline Sim & 35 & 97,22 \\
\hline Não & 1 & 2,78 \\
\hline \multicolumn{3}{|c|}{$\begin{array}{l}\text { Houve comentário sobre o material em reuniões com familiares/ } \\
\text { escola }\end{array}$} \\
\hline Sim & 23 & 63,89 \\
\hline Não & 12 & 33,33 \\
\hline Sem resposta & 1 & 2,78 \\
\hline \multicolumn{3}{|c|}{ Os alunos levaram o material para casa } \\
\hline $\operatorname{Sim}$ & 35 & 97,22 \\
\hline Não & 1 & 2,78 \\
\hline \multicolumn{3}{|c|}{ O que acharam da qualidade das cartilhas } \\
\hline Boa & 2 & 5,56 \\
\hline Ótima & 14 & 38,89 \\
\hline Excelente & 20 & 55,55 \\
\hline \multicolumn{3}{|c|}{ Você gostaria de continuar utilizando a coleção no próximo ano } \\
\hline Sim & 35 & 97,22 \\
\hline Não & 0 & 0,00 \\
\hline Talvez & 1 & 2,78 \\
\hline
\end{tabular}

A disciplina em que foram mais inseridos os temas da coleção "Se Liga Galera" em seu conteúdo foi Ciências (31 escolas). A seguir, vieram as disciplinas Artes (20 escolas) 
e Português (18 escolas). Das 32 escolas participantes, apenas uma não inseriu o tema na disciplina de Ciências, essa foi a pertencente ao município de Maricá.

Com relação às histórias da coleção e sua relação com a realidade dos educandos, $100 \%$ dos professores assinalaram afirmativamente, alegando ainda em total maioria que após o estudo seus alunos seriam capazes de difundi-las para seus familiares e comunidade em geral, adequando o aprendizado ao seu cotidiano.

Referente à compreensão dos alunos sobre os temas, todos os professores responderam que sim, justificando que tal assimilação foi demonstrada por meio dos trabalhos apresentados ao final do ano letivo, sejam esses, redações, cartazes, desenhos dos personagens feitos para a festa de encerramento, maquetes sobre os vários temas, jogos de memória, quebra-cabeça e apostilas a respeito das doenças; e pelos acertos de questões formuladas pelos educadores acerca dos temas.

Quanto à percepção do educador para com os alunos sobre um conhecimento inicial dos temas dispostos na coleção, 35 (97,22\%) dos educadores responderam que seus alunos já tinham ouvido falar sobre os assuntos e que tiveram interesse em debatê-los. Apenas um $(2,78 \%)$ dos educadores, pertencente ao município de Maricá, respondeu que os seus alunos já tinham ouvido falar acerca dos temas, mas não expressaram interesse em discuti-los em sala de aula.

No indicador sobre comentários dos temas da coleção nas reuniões familiares na escola, 23 (63,89\%) educadores responderam afirmativamente, contra 12 (33,33\%) que responderam negativamente. Deixou de responder a essa questão apenas um (2,78\%) educador. Dos 36 educadores que participaram da pesquisa, $35(97,22 \%)$ responderam que os alunos levaram o material para casa e apenas um (2,78\%) respondeu que seus alunos não levaram.

Quanto à qualidade da editoração, ilustração, impressão e acabamento das cartilhas, dois (5,56\%) educadores consideraram "boa", 14 (38,89\%) "ótima" e 20 (55,55\%) "excelente".

Perguntou-se, ao final, se eles gostariam de continuar utilizando a coleção "Se Liga Galera", dando continuidade às ações do projeto, $35(97,22 \%)$ responderam que sim e um $(2,78 \%)$ respondeu que talvez, justificando sua resposta de próprio punho com a observação de que "o conteúdo da capacitação foi o mesmo das cartilhas".

Por intermédio das respostas desses indicadores pôde-se validar a aceitação e percepção dos educadores e educandos das escolas públicas rurais do Ensino Fundamental sobre a coleção "Se Liga Galera" e suas cartilhas.

Durante as capacitações, discussões e monitoramento do projeto, tornou-se possível o diálogo com os educadores, e dois deles traduziram em seus discursos o que todos consideraram sobre o material didático, o desenvolvimento das ações e a receptividade por parte dos educandos.

De acordo com o primeiro educador, o material foi muito importante para os seus alunos, carentes de quase tudo na área rural, que são crianças que nunca saíram da região, trabalhando nas fazendas e auxiliando seus pais na renda familiar. Eles fizeram questão de levar o material para casa e contaram as histórias para seus pais, amigos, parentes e para todos da fazenda onde trabalhavam; também brincaram de teatro, simulando as histórias que aprenderam.

O segundo educador observou que seus alunos gostaram muito, principalmente sobre os temas Raiva e Alimentos Seguros. E dessa forma, organizaram um passeio ao supermer- 
cado local para que todos observassem tudo que aprenderam na história sobre alimentos seguros; eles adoraram a ideia, mas infelizmente encontraram vários produtos vencidos e sem refrigeração. O próprio educador revelou: "E não conseguimos observar tudo que gostaríamos, pois o dono do supermercado disse que estávamos atrapalhando as vendas e acabamos sendo convidados a nos retirar do recinto".

Alguns educadores escreveram no próprio questionário vários elogios parabenizando a pesquisa e que gostariam muito de dar continuidade ao projeto.

\section{CONSIDERAÇÕES FINAIS}

Em conformidade com os resultados obtidos, pode-se concluir que os objetivos desta investigação foram alcançados, do mesmo modo que as questões levantadas foram respondidas; pois, segundo ficou demonstrado, os instrumentos utilizados na proposta de educação sanitária da SEAPEC/RJ suscitaram novos conhecimentos para os profissionais de ensino, bem como, a percepção e o interesse nos respectivos alunos do Ensino Fundamental.

Os métodos e técnicas apresentados na capacitação, os debates, as exposições e as atividades interdisciplinares desenvolvidas contribuíram com a ampliação do conhecimento sobre os conteúdos acerca de sanidade animal e vegetal.

O desfecho obtido na presente pesquisa também demonstrou que é possível contar com a ação participativa dos educadores escolares, atuando na multiplicação de informações e conhecimentos sobre educação em saúde junto aos seus educandos, bem como, viabilizar, a partir da interface saúde/educação, o desenvolvimento de tomada de consciência sanitária desde o Ensino Fundamental, mesmo em escolas rurais desprovidas de recursos sofisticados.

Nesse caminhar, é possível utilizar medidas simples, mas que oportunizem resultados significativos na busca contínua pela melhoria da qualidade de vida.

A pesquisa apontou para o fato de que os professores detinham certo domínio acerca dos temas avaliados, conforme observado nos resultados da média geral de acertos da pré-capacitação $(60,07 \%)$. Entretanto, para se buscar na escola a contribuição para difusão dos temas relativos à educação sanitária, é necessário "manter acesa a chama", e disponibilizar aos professores capacitações constantes e formações continuadas mais aprofundadas, além de material didático contextualizado e de qualidade.

Espera-se que esta pesquisa traga contribuições para outros trabalhos em educação sanitária no âmbito dos temas locais, uma vez que não há muitas pesquisas semelhantes, e que possa também contribuir para o encorajamento de novas práticas pedagógicas, servindo como subsídio para futuras pesquisas de mestrado e/ou doutorado dentro da multidisciplinaridade que nossa proposta perquiriu.

\section{REFERÊNCIAS}

BARDIN, Laurence. Análise de Conteúdo. Lisboa: Edições 70, 2009. 
BRASIL. Parecer n. ${ }^{\circ}$ 4, de 29 de janeiro 1998. Estabelece as Diretrizes Curriculares Nacionais para o Ensino Fundamental. Diário Oficial da União, Brasília, DF, 30 mar. 1998.

BRASIL. Resolução n. ${ }^{\circ}$ 466, de 12 de dezembro de 2012. Dispõe sobre as diretrizes e normas regulamentadoras de pesquisas envolvendo seres humanos. Diário Oficial da União, Brasília, DF, 13 jun. 2013. Seção 1, p. 59.

FÁVERO, Osmar. Materiais Didáticos para a Educação de Jovens e Adultos. Cadernos Cedes, Campinas, v. 27, n. 71, p. 39-62, jan./abr. 2007. Disponível em: http://www.scielo. br/pdf/ccedes/v27n71/a04v2771.pdf. Acesso em: 15 mai. 2019.

FONSECA, João José Saraiva. Metodologia da pesquisa científica. Fortaleza: Universidade Estadual do Ceará, 2002.

FRAGA, Lívia dos Santos; CARDOSO, Karen Medeiros; PFUETZENREITER, Márcia Regina. As práticas docentes e abordagem sobre zoonoses no Ensino Fundamental. In: ENCONTRO NACIONAL DE PESQUISA EM EDUCAÇÃO EM CIÊNCIAS, VII., 2009, Florianópolis. Anais... Florianópolis: Associação Brasileira de Pesquisa em Educação em Ciências, 2009.

FREITAS, Carlos Machado de; GARCIA, Eduardo Garcia. Trabalho, saúde e meio ambiente na agricultura. Revista Brasileira de Saúde Ocupacional, São Paulo, v. 37, n. 125, p. 12-16, jan./jun. 2012. Disponível em: http://www.scielo.br/scielo.php?script=sci_arttext\&pid=S0303-76572012000100003. Acesso em: 18 jan. 2019.

GODOY, Arilda Schmidt. Introdução à pesquisa qualitativa e suas possibilidades. Revista de Administração de Empresas, São Paulo, v. 35, n. 2, p. 57-63, mar./abr. 1995. Disponível em: http://www.scielo.br/pdf/rae/v35n2/a08v35n2.pdf. Acesso em: 22 mar. 2019.

HIJJAR, Miguel Aiub. Tuberculose: desafio permanente. Cadernos de Saúde Pública, Rio de Janeiro, v. 21, n. 2, p. 348-349, mar./abr. 2005. Disponível em: http://www.scielo. br/pdf/csp/v21n2/01.pdf. Acesso em: 12 mar. 2019.

LEONELLO, Valéria Marli; L’ABBATE, Solange. Educação em Saúde na escola: uma abordagem do currículo e da percepção de alunos de graduação em Pedagogia. Interface - Comunicação, Saúde, Educação, Botucatu, v. 10, n. 19, p. 149-166, jan./jun. 2006. Disponível em: http://www.scielo.br/scielo.php?pid=S1414-32832006000100011\&script=sci_abstract\&tlng=pt. Acesso em: 12 jan. 2019.

MAIA, Vanessa Freires; VIEIRA, Cinthia Joizy de Oliveira; AMORIM, Letícia Alves; ANDRADE, Anny Suelen dos Santos; MACÊDO, Sonaly Melo; BEZERRA E SILVA, Sandy Yasmine; MEDEIROS, Eliabe Rodrigues; PINTO, Erika Simone Galvão. Conhecimento de estudantes da rede pública de ensino sobre a Tuberculose. Revista de Enfermagem 
UFPE, Recife, v. 11, n. 12, p. 4.781-4.788, dez. 2017. Disponível em: https://www.researchgate.net/publication/321735513_Conhecimento_de_estudantes_da_rede_publica_de_ ensino_sobre_a_tuberculose. Acesso em: 22 dez. 2018.

MARCONI, Marina de Andrade; LAKATOS, Eva Maria. Metodologia do trabalho científico. São Paulo: Atlas, 2017.

MARQUES, Elias Pereira. Educação, Saúde, Meio Ambiente e Políticas Públicas: o que pensam os professores? 2007, 233f. Dissertação (Mestrado em Saúde Pública) - Universidade de São Paulo, São Paulo, 2007.

MINISTÉRIO DA EDUCAÇÃO. Ciências: livro do estudante: Ensino Fundamental. Brasília: Ministério da Educação e Cultura/Instituto Nacional de Estudos e Pesquisas Educacionais Anísio Teixeira, 2006.

MOUTINHO, Flavio Fernando Batista; NASCIMENTO, Elmiro Rosendo; PAIXÃO, Rita Leal. Raiva no Estado do Rio de Janeiro, Brasil: análise das ações de vigilância e controle no âmbito municipal. Ciência \& Saúde Coletiva, Rio de Janeiro, v. 20, n. 2, p. 577-586, fev. 2015. Disponível em: http://www.scielo.br/pdf/csc/v20n2/1413-8123-csc-20-02-0577. pdf. Acesso em: 12 jan. 2019.

OLIVEIRA, Adriana Sindra da Silva; Bezerra, F. F. M.; Azevedo, F. R. M. A. Descrição do perfil epidemiológico da raiva no Estado do Rio de Janeiro no período de 1981 a 2007. Revista Rede de Cuidados em Saúde, Rio de Janeiro, v. 4, n. 2, p. 1-12, dez. 2010. Disponível em: file://C:/Users/usuario/Downloads/1071-3085-2-PB.pdf. Acesso em: 22 mar. 2019.

PLANK, David Nathan. Política educacional no Brasil: caminhos para a salvação pública. Porto Alegre: Artmed Editora Ltda, 2001.

RICHARDSON, Roberto Jarry. Pesquisa social: métodos e técnicas. São Paulo: Atlas, 2018.

SÁNCHEZ, Alba Idaly Muñoz; BERTOLOZZI, Maria Rita. Conhecimento sobre a tuberculose por estudantes universitários. Boletim de Pneumologia Sanitária, Rio de Janeiro, v. 12, n. 1, p. 17-24, abr. 2004. Disponível em: http://scielo.iec.gov.br/pdf/bps/v12n1/ v12n1a04.pdf. Acesso em: 22 mar. 2019.

SEAPEC-RJ. Agricultura, pecuária, pesca e abastecimento. Sanidade Rio. Disponível em: http://www.crmvrj.org.br/forum\%20de\%20saude $\% 20$ publica/educacao $\% 20$ sanitaria\%20e\%20meio\%20ambiente.pdf. Acesso em: 14 out. 2018a.

SEAPEC-RJ. Agricultura produz cartilhas para educação sanitária nas escolas rurais. Disponível em: http://www.rj.gov.br/web/seapec/exibeconteudo?article-id=901676. Acesso em: 14 out. $2018 b$. 
SEVERINO, Antônio Joaquim. Metodologia do trabalho científico. São Paulo: Cortez, 2007.

TAVARES, Ariane Moreira; PINHEIRO NETO, José Elias. O subentendido nas histórias em quadrinhos e sua importância no processo de ensino-aprendizagem. Revista Temporis [Ação], Goiás, v. 16, n. 2, p. 469, set. 2016. Disponível em: file://C:/Users/usuario/Downloads/4701-Texto\%20do\%20artigo-19034-1-10-20161011\%20(1).pdf. Acesso em: 15 abr. 2019.

UCHÔA, Claudia Maria Antunes; SERRA, Cathia Maria Barrientos; MAGALHÃES, Ciléia de Melo; SILVA, Roger Magno Macedo; FIGLIUOLO, Letícia Pinto; LEAL, Cristianni Antunes; MADEIRA, Maria de Fátima. Educação em saúde: ensinamento sobre a leishmaniose tegumentar americana. Cadernos de Saúde Pública, Rio de Janeiro, v. 20, n. 4, p. 935-941, jul./ago. 2004. Disponível em: http://www.scielo.br/pdf/csp/v20n4/07.pdf. Acesso em: 16 abr. 2019.

\section{DADOS DOS AUTORES:}

\section{Rosa Maria Antunes}

Médica Veterinária. Mestre em Educação Agrícola. Coordenadora de Educação Sanitária Secretaria de Estado de Agricultura, Pecuária e Abastecimento do Rio de Janeiro/RJ-Brasil. rosa-antunes@uol.com.br

\section{Argemiro Sanavria}

Médico Veterinário. Doutor em Ciências Veterinárias. Professor do Programa de Pós-Graduação em Educação Agrícola. Universidade Federal Rural do Rio de Janeiro. Seropédica/ RJ - Brasil. argemirosanavria@yahoo.com.br

\section{Ana Cristina Souza dos Santos}

Doutora em Química. Professor do Programa de Pós- Graduação em Educação Agrícola. Universidade Federal Rural do Rio de Janeiro. Seropédica/RJ - Brasil. anacrissantos.ufrrj@yahoo.com.br

\section{GiLmar Ferreira Vita}

Biólogo. Pós-Doutorando do Programa de Pós-Graduação em Educação Agrícola. Universidade Federal Rural do Rio de Janeiro Seropédia/RJ-Brasil.gilmarferreiravita@yahoo. com.br

Submetido em: 4-7-2019

Aceito em: 13-3-2020 